\title{
LGBT Coverage in U.S. Dental Schools and Dental Hygiene Programs: Results of a National Survey
}

\author{
Kenneth L. Hillenburg, DDS, MS; Carol A. Murdoch-Kinch, DDS, PhD; \\ Janet S. Kinney, RDH, MS; Henry Temple, DDS; Marita R. Inglehart, Dr phil habil
}

Abstract: The aims of this study were to assess curricular coverage of lesbian, gay, bisexual, and transgender (LGBT) content in U.S. and Canadian dental schools and U.S. dental hygiene programs, including hours of LGBT content, pedagogy used, and assessment methods, and to determine whether respondents perceived their institution's coverage as adequate. Data were collected from academic deans at 32 U.S. and two Canadian dental schools and from program directors at 71 U.S. dental hygiene programs (response rates $49 \%, 20 \%, 23 \%$, respectively). The results showed that $29 \%$ of responding dental schools and $48 \%$ of responding dental hygiene programs did not cover LGBT content. Among the respondents, dental schools dedicated on average 3.68 hours and dental hygiene programs 1.25 hours in required settings to LGBT content. Lectures (dental schools $68 \%$, dental hygiene programs 45\%) and small group instruction (43\%, 25\%) were reported as the most common methodology used in teaching this content. Most of the responding dental schools and dental hygiene programs covered HIV (85\%, 53\%), oral disease risk (63\%, $54 \%)$, and barriers to accessing health care for LGBT people $(58 \%, 38 \%)$. Up to a third reported no need for coverage of topics such as sexual orientation $(21 \%, 32 \%)$, coming out $(29 \%, 37 \%)$, transitioning $(29 \%, 38 \%)$, and sex reassignment surgery $(32 \%$, $35 \%)$. Assessment was through written examinations $(41 \%, 30 \%)$ and faculty-observed patient interactions $(21 \%, 23 \%)$; some respondents $(20 \%, 33 \%)$ reported no assessment of learning outcomes. The most frequently endorsed strategies for increasing LGBT content were receiving curricular material focusing on LGBT-related health issues and health disparities and having trained faculty to teach LGBT content.

Dr. Hillenburg is Adjunct Clinical Professor, University of Detroit Mercy School of Dentistry; Dr. Murdoch-Kinch is Clinical Professor and Associate Dean for Academic Affairs, University of Michigan School of Dentistry; Prof. Kinney is Associate Professor, Research Scientist, and Director of Dental Hygiene Program, Department of Periodontics and Oral Medicine, University of Michigan School of Dentistry; Dr. Temple is Clinical Assistant Professor, Department of Periodontics and Oral Medicine, University of Michigan School of Dentistry; and Dr. Inglehart is Professor of Dentistry, Department of Periodontics and Oral Medicine, School of Dentistry and Adjunct Professor, Department of Psychology, College of Literature, Science, and Arts, University of Michigan. Direct correspondence to Dr. Marita R. Inglehart, Department of Periodontics and Oral Medicine, University of Michigan School of Dentistry, 1011 N. University Ave., Ann Arbor, MI 48109-1078; 734-763-8073; mri@umich.edu.

Keywords: dental education, dental hygiene education, sexual orientation, sexuality, LGBT

Submitted for publication 2/18/16; accepted 6/20/16

$\mathrm{I}$ n 2014, an analysis of the results of four large, national, population-based surveys (National Survey of Family Growth, General Social Survey, National Health Interview Survey, and Gallup Daily Tracking Survey) reported that $2.2 \%$ to $4 \%$ of all respondents and $2.8 \%$ to $5.6 \%$ of $18-44$-year-old respondents self-identified as lesbian, gay, bisexual, or transgender (LGBT). ${ }^{1}$ These percentages show that a significant proportion of U.S. adults self-identify as LGBT. In the medical domain, health disparities affecting LGBT individuals have been carefully documented. Physical health disparities include increased prevalence of asthma, ${ }^{2}$ certain types of cancer, ${ }^{3}$ cardiovascular health, ${ }^{2,4}$ and risk of becoming disabled. ${ }^{5}$ Mental health disparities include increased risk of depression, ${ }^{6,7}$ suicide ideation and attempts, ${ }^{6,8,9}$ and substance use disorders. ${ }^{6,10}$ Risk behavior disparities related to increased smoking prevalence, ${ }^{11}$ increased risk of misuse of prescription opioids and tranquilizers, ${ }^{10}$ and behavior related to sexual activities ${ }^{12,13}$ and weight control ${ }^{14}$ are also supported by solid empirical research. In addition to recognizing these health disparities, it is crucial to acknowledge the documented challenges of LGBT individuals in accessing health care services and the denial of care that especially transgender individuals still experience in the U.S. ${ }^{15}$ The 2011 Institute of Medicine report The Health of Lesbian, Gay, Bisexual, and Transgender People focused attention on these issues ${ }^{15}$ and may have at least in part inspired the Association of American Medical Colleges (AAMC)'s 2014 resource for medical educators on curricular and institutional changes for individuals who are LGBT, gender nonconforming, or born with disorders of sex development. ${ }^{16}$ 
In dentistry and especially in dental education, research on the oral health status of LGBT individuals has not received much attention. Past research largely focused on one subgroup of LGBT individualsthose who are among patients diagnosed with HIV/ AIDS - and mostly on psychosocial issues related to providing care for those patients. ${ }^{17-21}$ There is clear evidence that people living with HIV/AIDS can experience potentially painful and health-compromising oral conditions such as oral lesions due to oral candidiasis or Kaposi's sarcoma. ${ }^{22}$ However, a solid study of issues affecting access to dental care for LGBT individuals outside of dental school clinics is still lacking. Since 1993, several studies have addressed the situation in dental school clinics and explored dental and dental hygiene students' attitudes towards patients with HIV/AIDS and their related knowledge and behavior/behavioral intentions. ${ }^{23-28}$ This research showed that, despite progress over the years, further improvement is needed in educating future dental care providers about these patients. ${ }^{19,29}$ This finding raises the question of how and how well dental schools and dental hygiene programs are educating their students about LGBT-related content.

One response to this question is to consider graduating seniors' responses to the question of how well their education/training has taught them about oral health care for LGBT groups. In 2014, 4.7\% of 4,541 graduating dental seniors responded to this question that they felt underprepared and 12.9\% that they were somewhat underprepared, while the majority $(54.2 \%)$ felt prepared or even well prepared $(21.4 \%) .{ }^{30}$ While these evaluations were quite positive, they do not provide information about which curricular coverage of LGBT content is provided in U.S. and Canadian dental schools and U.S. dental hygiene programs, nor how many hours of LGBT content is included in these programs and which pedagogy is used. An exemplary study of these issues in medical school curricula published in 2011 was conducted by Obedin-Maliver et al. ${ }^{31}$ Those authors granted permission to us to use their survey, revise it, and administer it to dental school and dental hygiene program administrators. Therefore, the aims of our dental school and dental hygiene program survey were to assess curricular coverage of LGBT content in these programs, number of hours spent on LGBT content, pedagogy used, and assessment of learning outcomes and to explore whether program administrators perceived this coverage to be adequate and what strategies for increasing LGBT content they would recommend.

\section{Methods}

This study was determined to be exempt from oversight by the Institutional Review Board for the Behavioral and Health Sciences at the University of Michigan (HUM00092970) on October 8, 2014. An a priori power analysis with the program package G*Power 3.1.2 (www.psycho.uni-duesseldorf.de/ abteilungen/aap/gpower3) was used to determine the sample size needed to have the power to test whether mean responses of these two independent samples and proportions of yes/no responses in these two independent samples were significantly different. When we assumed an alpha error of 0.05 , the power to be 0.80 , and a large effect size, the power analysis showed that 32 responses would be needed in each group. Given that 34 dental schools and 71 dental hygiene programs responded, we had the power to compare the average responses as well the frequencies for these two groups.

Participants from the dental schools were recruited via emails to the American Dental Education Association (ADEA) Section on Academic Affairs listserv, which includes all academic deans of dental schools in the U.S. and Canada in November 2014. This email informed the academic deans about the study and invited them to access the survey with a weblink provided in the message. One follow-up email was sent approximately two months later in January 2015. In addition, three academic deans completed paper and pencil surveys distributed at the ADEA Fall Meeting in Ft. Lauderdale, Florida, in October 2014.

Participants from the dental hygiene programs were recruited via individualized emails sent to all U.S. dental hygiene program directors in early 2015 , based on information from the American Dental Hygienists' Association website (www.adha.org/ resources-docs/71617_Entry_Level_Schools_By_ States.pdf). This message explained the purpose of the study and invited recipients to respond to the survey with a weblink in the message. A follow-up email was sent to the program directors in early summer of 2015.

The web-based, anonymous survey for both the dental school and dental hygiene program respondents was closely based on the Obedin-Maliver et al. survey designed to assess the curricular content of U.S. medical school programs. ${ }^{31}$ That survey was slightly revised, with permission of the authors, to include oral health-related content and to determine 
the characteristics of the dental schools and dental hygiene programs. It was then piloted with five dental and two dental hygiene faculty members. Based on this feedback, some minor revisions were made. The survey was then uploaded to the University of Michigan UM Lessons website, which allows collecting anonymous survey data.

The survey began with questions about the school/program characteristics, such as the number of students enrolled and the length of dental hygiene programs. The next section asked how many total hours were dedicated to teach LGBT content in required and elective settings and how the specific LGBT content was covered in the required curriculum. The next questions focused on LGBT-specific content coverage. The respondents received a list of 17 topics and were asked to indicate if those topics were covered, not covered, or the respondent did not know if they were covered. To ensure that all respondents used the same definitions for LGBT-related terms, a definition section was included in the survey that defined the following terms: sexual orientation, coming out, gender identity, intersex, transitioning, and sex reassignment surgery. In addition to asking whether these 17 topics were covered, a follow-up question inquired about the level of coverage and the respondent's perception of whether coverage was needed or not needed and whether there was too little coverage, adequate coverage, or too much coverage. The next question asked respondents' general opinion concerning the coverage of LGBT content at their school/program on a five-point scale ranging from $1=$ very poor to $5=$ very good. An additional question asked how the school/program assessed LGBTrelated learning outcomes.

Another question on the survey asked which strategies, in the respondent's view, would be successful in increasing LGBT-specific content at his or her institution. Nine options were listed, in addition to asking one open-ended question about strategies that the respondent considered to be successful. Two open-ended questions at the end asked respondents to describe problems and challenges to increasing the knowledge of LGBT-related health care topics at their institution and any other thoughts they may have about their school/program's curriculum coverage of LGBT topics.

The data were downloaded from the UM Lessons website as an Excel file and imported into SPSS, Version 22. The responses to the three paperand-pencil surveys were then added to this SPSS file. Descriptive statistics such as frequency distributions, percentages, means, and standard deviations were computed to provide an overview of the responses. The responses of the dental school academic deans versus those of the dental hygiene program directors were compared with inferential statistics. Chi-square analyses were used to analyze whether the frequency of yes/no answers in the two groups differed significantly. The answers to the open-ended questions were transcribed and independently coded by two of the authors. Any discrepancies were discussed and resolved. A $p<0.05$ was accepted as the level of significance.

\section{Results}

Of the academic deans at the 66 U.S. dental schools and ten Canadian dental schools who were invited to take part in the study, responses were received from 32 academic deans at U.S. schools (response rate 49\%) and two academic deans at Canadian schools (response rate 20\%) (Table 1). Of the 323 dental hygiene program directors in the U.S. who were invited to take part in the study, 71 responded (response rate $23 \%$ ).

The average number of students per year was 96 in the dental schools and 24 in the dental hygiene programs (Table 1). On average, the dental schools reported that $69 \%$ of their teaching pedagogy was traditional, $17 \%$ was case-based, and $15 \%$ was problem-based. Of the 71 dental hygiene programs, 34 were located at a community or junior college, 15 at a university or four-year college, ten at a dental school, eight at a technical college, and three at a school for allied health sciences. The type of dental hygiene degree granted was an associate degree for 48 programs and a baccalaureate degree for 21 programs; 58 of the dental hygiene programs had an undergraduate program, 22 a degree completion program, and ten a graduate program. The length of the dental hygiene programs ranged from eight to 70 months, with an average of 23 months. Although the response rate for the dental hygiene programs was lower than for the dental schools, these data showed that a wide range of dental hygiene programs participated in the study.

Table 2 provides an overview of the coverage of LGBT content by type of program. In response to the question "How many total hours are dedicated to LGBT content in required settings and elective settings?," the dental schools reported an average of 3.68 hours, and the dental hygiene programs reported an average of 1.25 hours. It should be mentioned that 
Table 1. Characteristics of participating dental schools $(\mathrm{N}=34)$ and dental hygiene programs $(\mathrm{N}=71)$

\begin{tabular}{|c|c|c|}
\hline Characteristic & Number/Mean & Percentage/SD (Range) \\
\hline $\begin{array}{l}\text { Number of participating } \\
\text { Dental schools in U.S. } \\
\text { Dental schools in Canada } \\
\text { Dental hygiene programs }\end{array}$ & $\begin{array}{l}\text { Number } \\
32 \\
2 \\
71\end{array}$ & $\begin{array}{c}\text { Response Rate } \\
49 \% \\
20 \% \\
23 \%\end{array}$ \\
\hline $\begin{array}{l}\text { Number of students per year } \\
\text { In dental schools } \\
\text { In dental hygiene programs }\end{array}$ & $\begin{array}{l}\text { Mean Number } \\
95.97 \\
24.14\end{array}$ & $\begin{array}{c}\text { SD (Range) } \\
61.26(23-380) \\
10.24(10-75)\end{array}$ \\
\hline $\begin{array}{l}\text { Dental schools' teaching pedagogy } \\
\text { Traditional } \\
\text { Case-based } \\
\text { Problem-based learning }\end{array}$ & $\begin{array}{l}\text { Mean \% } \\
68.8 \% \\
16.9 \% \\
14.9 \%\end{array}$ & $\begin{array}{c}\text { SD (Range) } \\
24.75 \%(0-95 \%) \\
12.19 \%(0-65 \%) \\
14.92 \%(0-100 \%)\end{array}$ \\
\hline Dental hygiene program information & Number & Percentage of Total \\
\hline $\begin{array}{l}\text { Educational setting } \\
\text { School of allied health sciences } \\
\text { Dental school } \\
\text { University or four-year college } \\
\text { Community or junior college } \\
\text { Technical college } \\
\text { For profit institution }\end{array}$ & $\begin{array}{c}3 \\
10 \\
15 \\
34 \\
8 \\
1\end{array}$ & $\begin{array}{c}4 \% \\
14 \% \\
21 \% \\
48 \% \\
11 \% \\
1 \%\end{array}$ \\
\hline $\begin{array}{l}\text { Type of degree granted } \\
\text { Diploma/certificate } \\
\text { Associate degree } \\
\text { Baccalaureate degree } \\
\text { Master's degree }\end{array}$ & $\begin{array}{c}0 \\
48 \\
21 \\
0\end{array}$ & $\begin{array}{c}0 \\
70 \% \\
30 \% \\
0\end{array}$ \\
\hline $\begin{array}{l}\text { Type of program } \\
\text { Undergraduate program } \\
\text { Degree completion program. } \\
\text { Graduate program }\end{array}$ & $\begin{array}{l}58 \\
22 \\
10\end{array}$ & $\begin{array}{l}94 \% \\
36 \% \\
16 \%\end{array}$ \\
\hline Length of program in months & $\begin{array}{l}\text { Mean } \\
23.31\end{array}$ & $\begin{array}{l}\text { SD (Range) } \\
9.37(8-70)\end{array}$ \\
\hline
\end{tabular}

the large standard deviations for the required and elective hours of coverage in dental schools were the result of having one school report exceptionally large hours of coverage in a problem-based learning (PBL) setting. In elective courses, the dental schools provided about two hours and the dental hygiene programs less than one hour of coverage.

Concerning the extent of coverage, $29 \%$ of responding dental schools and $48 \%$ of responding dental hygiene programs had no LGBT-content coverage at all, and $12 \%$ of the dental school respondents reported they did not know if the content was covered. Among the respondents, about half of the dental schools $(53 \%)$ and dental hygiene programs $(50 \%)$ reported that LGBT content was interspersed throughout various parts of their curricula, and 6\% of the dental schools and $3 \%$ of the dental hygiene programs responded that it was taught in discrete LGBT modules. When asked which pedagogy was used, $68 \%$ of these dental schools and $45 \%$ of these dental hygiene programs responded that it was provided in lectures, while small group sessions were used by $43 \%$ of the dental schools and $25 \%$ of the dental hygiene programs. In response to the question if faculty development for teaching LGBT content is provided, $36 \%$ of the dental schools and $28 \%$ of the dental hygiene programs responded positively. In response to the question "When learning how to conduct a medical/dental history, are your students taught to obtain information about same sex relations?," $21 \%$ of the dental school respondents and $10 \%$ of the dental hygiene program respondents responded positively. When asked "Are your students taught the difference between behavior and identity (e.g., a man may have sex with other men and identify as straight)?," $48 \%$ of the dental school respondents and $21 \%$ of the dental hygiene respondents agreed that they taught this difference $(\mathrm{p}=0.013)$.

The survey listed 17 specific LGBT content areas and asked respondents to indicate if their curricu- 


\begin{tabular}{|c|c|c|c|}
\hline LGBT Coverage and Content & Dental Schools & Dental Hygiene Programs & p-value \\
\hline Total hours dedicated to LGBT content & Mean (SD) & Mean (SD) & \\
\hline In required settings & $3.676(10.33)$ & $1.250(2.86)$ & 0.187 \\
\hline In elective settings & $2.059(8.33)$ & $0.779(2.87)$ & 0.390 \\
\hline In the required curriculum, LGBT-specific content is & $\mathrm{N}(\%)$ Yes & $\mathrm{N}(\%)$ Yes & 0.025 \\
\hline Interspersed throughout various parts & $18(53 \%)$ & $30(50 \%)$ & \\
\hline Taught in discrete LGBT modules & $2(6 \%)$ & $2(3 \%)$ & \\
\hline Not taught & $10(29 \%)$ & $29(48 \%)$ & \\
\hline Not known & $4(12 \%)$ & 0 & \\
\hline \multicolumn{4}{|l|}{ Pedagogy used } \\
\hline Lectures & $19(68 \%)$ & $29(45 \%)$ & 0.038 \\
\hline Small groups & $9(43 \%)$ & $16(25 \%)$ & 0.101 \\
\hline Others & $5(29 \%)$ & $8(13 \%)$ & 0.113 \\
\hline Faculty development for teaching LGBT content is provided. & $11(36 \%)$ & $16(28 \%)$ & 0.314 \\
\hline $\begin{array}{l}\text { When learning how to conduct a medical/dental history, } \\
\text { are your students taught to obtain information about } \\
\text { same-sex relations (e.g., asking "do you have sex with } \\
\text { men, women, both, or neither?")? }\end{array}$ & $5(21 \%)$ & $7(10 \%)$ & 0.154 \\
\hline $\begin{array}{l}\text { Are your students taught the difference between behavior } \\
\text { and identity (e.g., a man may have sex with other men and } \\
\text { identify as straight)? }\end{array}$ & $12(48 \%)$ & $13(21 \%)$ & 0.013 \\
\hline
\end{tabular}

la covered these topics. The most frequently covered topic was "HIV in LGBT people" (dental schools $85 \%$; dental hygiene programs $53 \%$; $\mathrm{p}=0.004$ ), followed by "sexually transmitted infections other than HIV in LGBT people" (dental schools 68\%; dental hygiene programs $48 \% ; \mathrm{p}=0.089$ ) and "oral health disease risk for LGBT populations" (dental schools $63 \%$; dental hygiene programs $54 \% ; p=0.302$ ) (Table $3)$. Slightly more than half of the responding dental schools educated their students about "barriers to accessing health care for LGBT people," "chronic disease risk for LGBT populations," "alcohol, tobacco, and other substance use among LGBT people," and "sexual orientation." However, lower percentages of these dental hygiene programs provided information about these topics. The least frequently covered topic was "sex reassignment surgery" (dental schools 14\%; dental hygiene programs $11 \%$; n.s.), "safer sex for LGBT people" (14\% vs. 25\%; n.s.), "LGBT pediatric and adolescent health" (22\% vs. $14 \%$; n.s.), and "body image in LGBT people" ( $24 \%$ vs. $9 \%$; n.s.).

Table 4 shows the percentages of respondents who indicated whether no coverage of these specific LGBT content areas was needed or if they perceived coverage was needed at their school/program, more coverage was needed, or the coverage was adequate. About a third of the dental hygiene programs reported that no coverage was needed for nine of the 17 content areas. The highest rate of agreement that coverage was needed was for the topics "barriers to accessing oral health care" and "LGBT pediatric and adolescent health." The only area in which more than half of the dental school respondents thought that the coverage was adequate was "HIV in LGBT people" $(53 \%)$. The topic "mental health in LGBT people" was perceived by $30 \%$ of the dental school respondents and $32 \%$ of the dental hygiene program respondents as needing more coverage. In response to a final question concerning the coverage of LGBT content on the whole, the respondents from both dental schools and dental hygiene programs considered the coverage to be slightly poor (on a five-point scale from $1=$ very good to $5=$ very poor: 3.70 vs. 3.49 ; n.s.) (Table 5).

According to these respondents, most of the participating institutions used written examinations $(41 \%$ dental schools vs. $30 \%$ dental hygiene programs) and faculty-observed patient interactions ( $21 \%$ vs. $23 \%)$ to assess learning outcomes concerning LGBT-specific content (Table 5). Peer-to-peer evaluations and evaluations by standardized patients or by patients were much less likely to be used as assessment methods.

A final closed-ended question asked the respondents to select strategies from a list of nine strategies that they perceived would be successful in increasing LGBT-specific content at their institution (Table 6). The most frequently selected strategy was 
Table 3. Inclusion of specific LGBT content in participating dental schools $(\mathrm{N}=34)$ and dental hygiene programs $(\mathrm{N}=71)$

\begin{tabular}{|c|c|c|c|}
\hline Specific LGBT Content & $\begin{array}{l}\text { Dental } \\
\text { Schools } \\
\text { N }(\%) \text { Yes }\end{array}$ & $\begin{array}{c}\text { Dental Hygiene } \\
\text { Program } \\
\text { N }(\%) \text { Yes }\end{array}$ & p-value \\
\hline HIV in LGBT people & $22(85 \%)$ & $32(53 \%)$ & 0.004 \\
\hline Sexually transmitted infections (not HIV) in LGBT people & $15(68 \%)$ & $28(48 \%)$ & 0.089 \\
\hline Oral health disease risk for LGBT populations & $17(63 \%)$ & $32(54 \%)$ & 0.302 \\
\hline Barriers to accessing health care for LGBT people & $15(58 \%)$ & $22(38 \%)$ & 0.074 \\
\hline Chronic disease risk for LGBT populations & $14(58 \%)$ & $21(38 \%)$ & 0.079 \\
\hline Alcohol, tobacco, or other substance use among LGBT people & $15(54 \%)$ & $17(32 \%)$ & 0.045 \\
\hline Sexual orientation & $14(54 \%)$ & $19(31 \%)$ & 0.036 \\
\hline Gender identity & $10(40 \%)$ & $14(23 \%)$ & 0.100 \\
\hline Mental health in LGBT people & $8(33 \%)$ & $11(20 \%)$ & 0.172 \\
\hline Disorders of sex development (DSD)/intersex & $8(32 \%)$ & $6(11 \%)$ & 0.022 \\
\hline Transitioning & $7(29 \%)$ & $7(12 \%)$ & 0.068 \\
\hline Unhealthy relationships (e.g., intimate partner violence) among LGBT people & $6(26 \%)$ & $17(30 \%)$ & 0.482 \\
\hline Coming out & $6(26 \%)$ & $8(14 \%)$ & 0.152 \\
\hline Body image in LGBT people & $6(24 \%)$ & $5(9 \%)$ & 0.077 \\
\hline LGBT pediatric and adolescent health & $5(22 \%)$ & $8(14 \%)$ & 0.286 \\
\hline Safer sex for LGBT people & $3(14 \%)$ & $14(25 \%)$ & 0.230 \\
\hline Sex reassignment surgery & $3(14 \%)$ & $6(11 \%)$ & 0.483 \\
\hline
\end{tabular}

Note: The survey provided the following definitions for respondents to use in answering questions:

Sexual orientation: an individual's self-identified state of physical and/or emotional attraction. "Heterosexual," "bisexual," and "homosexual" are all sexual orientations.

Coming out: a process of disclosure of one's sexual orientation or gender identity to oneself and/or others

Gender identity: A person's deeply felt psychological identification as male, female, transgender, no gender, or another gender, which may or may not correspond to the person's body or designated sex at birth.

Intersex: A general term used for a variety of conditions in which a person is born with reproductive or sexual anatomy that does not fit the typical definitions of female or male. This is also known as "disorders of sex development" (DSD). Though these terms are used by many, some consider them offensive and prefer such terms as "anatomic variation."

Transitioning: The process through which a person modifies physical characteristics and/or manner of gender expression to be consistent with gender identity. This process, also referred to as "gender affirmation," may include hormone therapy, sex reassignment surgery, and/ or other components and is generally conducted under medical supervision based on a set of standards developed by medical professionals.

Sex reassignment surgery: The alteration surgery that transgender individuals sometimes undergo to change their physical bodies to match their gender identities. This was previously referred to as a "sex change operation." This process is also referred to as "sex affirmation treatment."

to provide "curricular material focusing on LGBTrelated health/health disparities" (74\% dental school respondents vs. 55\% dental hygiene respondents) and having "faculty able and willing to teach LGBTrelated curricular content" ( $74 \%$ vs. $37 \%$; $p<0.001)$. "More evidence-based research regarding LGBT health/health disparities" was considered by a majority of both groups as a successful strategy (59\% vs. $54 \%$ ). "More time in the curriculum" was selected as a strategy by more dental schools (50\%) compared with the dental hygiene programs (32\%). "Increased financial resources" was seen as the strategy least likely to be successful (21\% vs. $14 \%)$.

\section{Discussion}

Previous research on LGBT-specific concerns in dental and dental hygiene education either ex- plored dental and dental hygiene students' attitudes towards patients with HIV/AIDS and their related knowledge and behavior/behavioral intentions ${ }^{23-28}$ or sought to gain a better understanding of students' perceptions of their LGBT-related educational experiences. ${ }^{28,30}$ Other studies explored the services that schools provided for LGBT students ${ }^{32,33}$ or investigated ways to provide better LGBT-specific education. ${ }^{19,20,29}$ No previous study had collected data on the LGBT-specific content of dental and dental hygiene curricula.

When dental students graduating in 2014 were asked how well their education/training had prepared them to provide oral health care for LGBT patients, $54.2 \%$ reported feeling prepared and $21.4 \%$ well prepared. ${ }^{30}$ However, the results of our survey raise the question of whether those students may "not know what they don't know" because their LGBT-specific education was likely to not have been extensive, 
Table 4. Perceptions of adequacy of coverage of specific LGBT content in their institution, by percentage of respondents from dental schools $(\mathrm{N}=34)$ and dental hygiene programs $(\mathrm{N}=71)$

\begin{tabular}{|c|c|c|c|c|c|c|}
\hline \multirow[b]{2}{*}{ Specific LGBT Content } & \multirow[b]{2}{*}{ School/Program } & \multicolumn{4}{|c|}{ Coverage } & \multirow[b]{2}{*}{ p-value } \\
\hline & & $\begin{array}{l}\text { Not } \\
\text { Needed }\end{array}$ & Needed & $\begin{array}{l}\text { More } \\
\text { Needed }\end{array}$ & Adequate & \\
\hline Barriers to accessing health care for LGBT people & $\begin{array}{l}\text { Dental } \\
\text { Dental hygiene }\end{array}$ & $\begin{array}{c}3 \% \\
19 \%\end{array}$ & $\begin{array}{l}50 \% \\
31 \%\end{array}$ & $\begin{array}{l}24 \% \\
27 \%\end{array}$ & $\begin{array}{l}24 \% \\
22 \%\end{array}$ & 0.086 \\
\hline $\begin{array}{l}\text { Alcohol, tobacco, or other substance use among } \\
\text { LGBT people }\end{array}$ & $\begin{array}{l}\text { Dental } \\
\text { Dental hygiene }\end{array}$ & $\begin{array}{c}6 \% \\
23 \%\end{array}$ & $\begin{array}{l}38 \% \\
29 \%\end{array}$ & $\begin{array}{l}18 \% \\
27 \%\end{array}$ & $\begin{array}{l}38 \% \\
20 \%\end{array}$ & 0.043 \\
\hline Safer sex for LGBT people & $\begin{array}{l}\text { Dental } \\
\text { Dental hygiene }\end{array}$ & $\begin{array}{l}24 \% \\
34 \%\end{array}$ & $\begin{array}{l}41 \% \\
28 \%\end{array}$ & $\begin{array}{l}6 \% \\
17 \%\end{array}$ & $\begin{array}{l}30 \% \\
22 \%\end{array}$ & 0.197 \\
\hline $\begin{array}{l}\text { Sexually transmitted infections (not HIV) in } \\
\text { LGBT people }\end{array}$ & $\begin{array}{l}\text { Dental } \\
\text { Dental hygiene }\end{array}$ & $\begin{array}{c}6 \% \\
15 \%\end{array}$ & $\begin{array}{l}44 \% \\
33 \%\end{array}$ & $\begin{array}{l}15 \% \\
24 \%\end{array}$ & $\begin{array}{l}35 \% \\
27 \%\end{array}$ & 0.288 \\
\hline HIV in LGBT people & $\begin{array}{l}\text { Dental } \\
\text { Dental hygiene }\end{array}$ & $\begin{array}{l}3 \% \\
17 \%\end{array}$ & $\begin{array}{l}27 \% \\
28 \%\end{array}$ & $\begin{array}{l}18 \% \\
23 \%\end{array}$ & $\begin{array}{l}53 \% \\
32 \%\end{array}$ & 0.096 \\
\hline Chronic disease risk for LGBT populations & $\begin{array}{l}\text { Dental } \\
\text { Dental hygiene }\end{array}$ & $\begin{array}{c}9 \% \\
14 \%\end{array}$ & $\begin{array}{l}44 \% \\
36 \%\end{array}$ & $\begin{array}{l}20 \% \\
27 \%\end{array}$ & $\begin{array}{l}27 \% \\
23 \%\end{array}$ & 0.726 \\
\hline Oral health disease risk for LGBT populations & $\begin{array}{l}\text { Dental } \\
\text { Dental hygiene }\end{array}$ & $\begin{array}{c}6 \% \\
14 \%\end{array}$ & $\begin{array}{l}41 \% \\
33 \%\end{array}$ & $\begin{array}{l}20 \% \\
23 \%\end{array}$ & $\begin{array}{l}32 \% \\
30 \%\end{array}$ & 0.640 \\
\hline Sexual orientation & $\begin{array}{l}\text { Dental } \\
\text { Dental hygiene }\end{array}$ & $\begin{array}{l}21 \% \\
32 \%\end{array}$ & $\begin{array}{l}38 \% \\
27 \%\end{array}$ & $\begin{array}{c}9 \% \\
18 \%\end{array}$ & $\begin{array}{l}32 \% \\
23 \%\end{array}$ & 0.262 \\
\hline Coming out & $\begin{array}{l}\text { Dental } \\
\text { Dental hygiene }\end{array}$ & $\begin{array}{l}29 \% \\
37 \%\end{array}$ & $\begin{array}{l}35 \% \\
26 \%\end{array}$ & $\begin{array}{l}12 \% \\
19 \%\end{array}$ & $\begin{array}{l}24 \% \\
19 \%\end{array}$ & 0.592 \\
\hline Gender identity & $\begin{array}{l}\text { Dental } \\
\text { Dental hygiene }\end{array}$ & $\begin{array}{l}21 \% \\
32 \%\end{array}$ & $\begin{array}{l}41 \% \\
26 \%\end{array}$ & $\begin{array}{c}9 \% \\
22 \%\end{array}$ & $\begin{array}{l}29 \% \\
20 \%\end{array}$ & 0.130 \\
\hline Disorders of sex development (DSD)/intersex & $\begin{array}{l}\text { Dental } \\
\text { Dental hygiene }\end{array}$ & $\begin{array}{l}24 \% \\
34 \%\end{array}$ & $\begin{array}{l}38 \% \\
28 \%\end{array}$ & $\begin{array}{l}18 \% \\
23 \%\end{array}$ & $\begin{array}{l}21 \% \\
15 \%\end{array}$ & 0.524 \\
\hline Transitioning & $\begin{array}{l}\text { Dental } \\
\text { Dental hygiene }\end{array}$ & $\begin{array}{l}29 \% \\
38 \%\end{array}$ & $\begin{array}{l}41 \% \\
28 \%\end{array}$ & $\begin{array}{c}9 \% \\
19 \%\end{array}$ & $\begin{array}{l}21 \% \\
16 \%\end{array}$ & 0.345 \\
\hline Sex reassignment surgery & $\begin{array}{l}\text { Dental } \\
\text { Dental hygiene }\end{array}$ & $\begin{array}{l}32 \% \\
35 \%\end{array}$ & $\begin{array}{l}41 \% \\
28 \%\end{array}$ & $\begin{array}{c}9 \% \\
23 \%\end{array}$ & $\begin{array}{l}18 \% \\
14 \%\end{array}$ & 0.259 \\
\hline LGBT pediatric and adolescent health & $\begin{array}{l}\text { Dental } \\
\text { Dental hygiene }\end{array}$ & $\begin{array}{c}9 \% \\
32 \%\end{array}$ & $\begin{array}{l}50 \% \\
29 \%\end{array}$ & $\begin{array}{l}29 \% \\
27 \%\end{array}$ & $\begin{array}{l}12 \% \\
12 \%\end{array}$ & 0.051 \\
\hline Mental health in LGBT people & $\begin{array}{l}\text { Dental } \\
\text { Dental hygiene }\end{array}$ & $\begin{array}{c}6 \% \\
27 \%\end{array}$ & $\begin{array}{l}44 \% \\
30 \%\end{array}$ & $\begin{array}{l}32 \% \\
30 \%\end{array}$ & $\begin{array}{l}18 \% \\
14 \%\end{array}$ & 0.091 \\
\hline Body image in LGBT people & $\begin{array}{l}\text { Dental } \\
\text { Dental hygiene }\end{array}$ & $\begin{array}{l}21 \% \\
39 \%\end{array}$ & $\begin{array}{l}41 \% \\
28 \%\end{array}$ & $\begin{array}{l}24 \% \\
25 \%\end{array}$ & $\begin{array}{l}15 \% \\
9 \%\end{array}$ & 0.253 \\
\hline $\begin{array}{l}\text { Unhealthy relationships (e.g., intimate partner } \\
\text { violence) among LGBT people }\end{array}$ & $\begin{array}{l}\text { Dental } \\
\text { Dental hygiene }\end{array}$ & $\begin{array}{l}18 \% \\
26 \%\end{array}$ & $\begin{array}{l}44 \% \\
25 \%\end{array}$ & $\begin{array}{l}21 \% \\
29 \%\end{array}$ & $\begin{array}{l}18 \% \\
20 \%\end{array}$ & 0.250 \\
\hline
\end{tabular}

Note: See note with Table 3 for definitions of terms provided to survey respondents. Percentages may not total $100 \%$ because of rounding.

comprehensive, and well rounded. In addition, it is unclear if those students were differentiating between being prepared to provide care for LGB patients (i.e., those with sexual orientations not strictly heterosexual) and their knowledge related to transgender/gender identity issues. Our survey found that large percentages of the responding dental schools $(29 \%)$ and dental hygiene programs (48\%) did not cover any LGBT-specific content in their required curricula. When they did so, they were most likely to address HIV and other sexually transmitted diseases (STD) in LGBT people. On the one hand, one could consider that even when HIV/AIDS and STD are being addressed, they might be covered without properly discussing the cultural competence required to treat people with minority sexual orientations 
Table 5. Respondents' overall opinion of LGBT coverage at their institution and assessment methods used with LGBTspecific content, by percentage of respondents from dental schools $(\mathrm{N}=34)$ and dental hygiene programs $(\mathrm{N}=71)$

\begin{tabular}{lccc} 
Item & Dental Schools & Dental Hygiene Programs & $p$-value \\
\hline & Mean (SD) & Mean (SD) & 0.399 \\
Overall opinion of LGBT coverage at institution & $3.70(1.09)$ & $3.49(1.09)$ & 0.181 \\
Assessment method used & $\%$ Yes & $30 \%$ & 0.517 \\
Written examination & $41 \%$ & $23 \%$ & 0.593 \\
Faculty-observed patient interactions & $21 \%$ & $7 \%$ & 0.191 \\
Peer-to-peer evaluations & $6 \%$ & $3 \%$ & 0.610 \\
Evaluation by standardized patients & $9 \%$ & $4 \%$ &
\end{tabular}

Note: Question for first item was worded as follows: Please describe your opinion of the coverage of LGBT content, on the whole, at your institution. Response options ranged from $1=$ very good to $5=$ very poor. On assessment method item, respondents could select all that applied.

Table 6. Strategies that would be successful in increasing LGBT-specific content at their institution, by percentage of respondents from dental schools $(\mathrm{N}=34)$ and dental hygiene programs $(\mathrm{N}=71)$

\begin{tabular}{|c|c|c|c|}
\hline Strategy & $\begin{array}{l}\text { tal Schools } \\
\% \text { Yes }\end{array}$ & $\begin{array}{l}\text { Dental Hygiene Programs } \\
\% \text { Yes }\end{array}$ & p-value \\
\hline Curricular material focusing on LGBT-related health/health disparities & $74 \%$ & $55 \%$ & 0.052 \\
\hline Faculty willing and able to teach LGBT-related curricular content & $74 \%$ & $37 \%$ & $<0.0001$ \\
\hline More evidence-based research regarding LGBT health/health disparities & $59 \%$ & $54 \%$ & 0.383 \\
\hline More time in the curriculum to be able to teach LGBT-related content & $50 \%$ & $32 \%$ & 0.064 \\
\hline Curricular material coverage required by accreditation bodies & $44 \%$ & $35 \%$ & 0.252 \\
\hline Logistical support for teaching LGBT-related curricular content & $29 \%$ & $21 \%$ & 0.243 \\
\hline $\begin{array}{l}\text { Questions based on LGBT health/health disparities on national examinations } \\
\text { (e.g., NBDE Parts I and II) }\end{array}$ & $29 \%$ & $20 \%$ & 0.194 \\
\hline Methods to evaluate LGBT curricular content & $27 \%$ & $32 \%$ & 0.387 \\
\hline Increased financial resources & $21 \%$ & $14 \%$ & 0.282 \\
\hline Don't know & $3 \%$ & $11 \%$ & 0.145 \\
\hline
\end{tabular}

Note: Item asked respondents to respond yes/no regarding their perceptions of "strategies that would be successful in increasing LGBTspecific content at your institution."

or gender identity who suffer from those diseases. Future research needs to address these concerns. On the other hand, associating LGBT content with HIV/ AIDS and STDs could continue the destructive cycle of stigmatization of LGBT people. ${ }^{34}$

This distinction raises the question of which strategies might be successful in increasing appropriate LGBT-specific content coverage. Most respondents in both types of programs suggested that having curricular material focusing on LGBTrelated health/health disparities would be a beneficial strategy. However, the lack of solid evidence-based research concerning oral health issues among LGBT people is one obstacle in this context. While the 2011 report by the Institute of Medicine's Committee on Lesbian, Gay, Bisexual, and Transgender Health Issues and Research Gaps and Opportunities thoroughly presented the health issues of lesbian, gay, bisexual, and transgender people, ${ }^{15}$ there is no equivalent effort in the oral health sciences. Future research is urgently needed because addressing the concerns of LGBT patients is needed to comply with Commission on Dental Accreditation (CODA) Standard 2-16, "Graduates must be competent in managing a diverse patient population and have the interpersonal and communications skills to function successfully in a multicultural work environment, ${ }^{35}$ as well as with the Dental Hygiene Code of Ethics because of the critical role that risk assessment and health promotion play in the ethical responsibility of the dental hygiene profession. ${ }^{36}$

Finally, a comparison of our results with the findings of Obedin-Maliver et al. ${ }^{31}$ in medical school settings shows some interesting differences but also 
some striking similarities. One difference is the fact that only $6.9 \%$ of the 132 medical schools $(\mathrm{N}=9)$ surveyed did not have any coverage of LGBT content in the preclinical years. This finding shows that medical schools are much more likely than dental schools and dental hygiene programs to address these issues. However, it is interesting that the two most frequently cited strategies for successfully increasing LGBT content in all three health professions programs were identical. Respondents in all three types of programs were most likely to choose having curricular material focusing on LGBT people plus having faculty members willing and able to teach LGBT-related content as two strategies most likely to increase LGBT coverage. For medical educators, the 2014 AAMC report provided the best possible response to the first strategy. ${ }^{16}$ While many of the resources listed in this report are applicable to dental and dental hygiene education as well, oral health-specific efforts should definitely be developed. We suggest that members of the ADEA Gay-Straight-Alliance Section could play an important role in this endeavor.

This study had several limitations. First, the relatively low response rates of $49 \%$ of U.S. dental schools, $20 \%$ of Canadian dental schools, and $23 \%$ of U.S. dental hygiene programs were not optimal. However, given the findings by Hardigan et al. concerning response rates to web-based (11\%) and postal/mailed surveys $(26 \%),{ }^{37}$ these response rates are not unusually low. Future research should therefore consider using mailed surveys to receive a higher response rate. In addition, these low response rates might be an indicator of a lack of interest in the LGBT topic. Such a lack of interest can be also seen in the following comment by a dental hygiene program director in response to our recruitment email: "Please take me off the survey list for this topic. We do not address this with or about our students. We are in the business of education." A second limitation is the subjectivity of survey responses. Future research could focus on conducting a curriculum analysis that might result in more objective data. Additionally, it would be helpful to triangulate these findings with results from student and faculty surveys. A third limitation is the lack of data from Canadian dental hygiene programs. One final limitation is that this study focused only on LGBT issues and did not include questions concerning gender nonconforming people nor the role of diversity-related educational efforts in clinical settings. Future research should address these important aspects of our students' education.

\section{Conclusion}

This study found that almost half of the responding dental hygiene programs (48\%) and three out of ten responding dental schools did not teach any LGBT-specific content in their required curricula. In addition, about a third of the responding dental hygiene program directors did not consider that the majority of LGBT-specific topics needed to be covered in their curricula. The topics most likely to be addressed were HIV in LGBT people and sexually transmitted infections other than HIV in LGBT people. The topic least likely to be addressed was sex reassignment surgery. If LGBT topics were addressed, lectures were the most commonly used teaching approach. Strategies perceived as being successful in increasing LGBT-specific content at their institutions were curricular material focusing on LGBT health/health disparities and faculty willing and able to teach LGBT-related curricular content. The respondents also reported feeling that more evidence-based research regarding LGBT health/ health disparities would be helpful as well. Overall, only a few programs provided education related to the comprehensive needs of LGBT patients.

\section{Acknowledgments}

We thank Dr. Obedin-Maliver and her colleagues for generously granting us permission to use their survey of LGBT content coverage in medical school curricula for our project. We also thank the dental school administrators and dental hygiene program directors who responded to this survey.

\section{REFERENCES}

1. Gates GJ. LGB/T demographics: comparisons among population-based surveys. Williams Institute, UCLA School of Law, 2014. At: williamsinstitute.law.ucla.edu/ wp-content/uploads/lgbt-demogs-sep-2014.pdf. Accessed 10 Feb. 2016.

2. Conron KJ, Mimiage MJ, Landers SJ. A population-based study of sexual orientation identity and gender differences in adult health. Am J Public Health 2010;100(10):1953-60.

3. Darwich L, Videla S, Canadas MP, et al. Distribution of human papillomavirus genotypes in anal cytological and histological specimens from HIV-infected men who have sex with men and men who have sex with women. Dis Colon Rectum 2013;56(9):1043-52.

4. Hatzenbuehler ML, McLaughlin KA, Slopen N. Sexual orientation disparities in cardiovascular biomarkers among young adults. Am J Prev Med 2013;44(6):612-21.

5. Fredriksen-Goldsen KI, Kim HJ, Barkan SE. Disability among lesbian, gay, and bisexual adults: disparities in 
prevalence and risk. Am J Public Health 2012;102(1): e16-21.

6. Lewis NM. Mental health in sexual minorities: recent indicators, trends, and their relationships to place in North America and Europe. Health Place 2009;15(4):1029-45.

7. Bazargan M, Galvan F. Perceived discrimination and depression among low-income Latina male-to-female transgender women. BMC Public Health 2012;12:663.

8. Marshal MP, Dietz LJ, Friedman MS, et al. Suicidality and depression disparities between sexual minority and heterosexual youth: a meta-analytic review. J Adolesc Health 2011;49(2):115-23.

9. King M, Semlyen J, Tai SS, et al. A systematic review of mental disorder, suicide, and deliberate self harm in lesbian, gay, and bisexual people. BMC Psychiatry 2008;8:70

10. Kecojevic A, Wong CF, Schrager SM, et al. Initiation into prescription drug misuse: differences between lesbian, gay, bisexual, transgender (LGBT) and heterosexual highrisk young adults in Los Angeles and New York. Addict Behav 2012;37(11):1289-93.

11. Lee JG, Blosnich JR, Melvin CL. Up in smoke: vanishing evidence of tobacco disparities in the Institute of Medicine's report on sexual and gender minority health. Am J Public Health 2012;102(11):2041-3.

12. Rhodes SD, McCoy T, Hergenrather KC, et al. Exploring the health behavior disparities of gay men in the United States: comparing gay male university students to their heterosexual peers. J LGBT Health Res 2007;3(1):15-23.

13. Thoma BC, Huebner DM, Rullo JE. Unseen risks: HIV-related risk behaviors among ethnically diverse sexual minority adolescent females. AIDS Educ Prev 2013;25(6):535-41.

14. Hadland SE, Austin SB, Goodenow CS, Calzo JP. Weight misperception and unhealthy weight control behaviors among sexual minorities in the general adolescent population. J Adolesc Health 2014;54(3):296-303.

15. Institute of Medicine Committee on Lesbian, Gay, Bisexual, and Transgender Health Issues and Research Gaps and Opportunities. The health of lesbian, gay, bisexual, and transgender people: building a foundation for better understanding. Washington, DC: National Academies Press, 2011.

16. Hollenbach AD, Eckstrand KL, Dreger A. Implementing curricular and institutional climate changes to improve health care for individuals who are LGBT, gender nonconforming, or born with DSD: a resource for medical educators. 2014. At: members.aamc.org/eweb/upload/ LGBTDSD\%20Publication.pdf. Accessed 10 Feb. 2016.

17. Seacat JP, Inglehart MR. Education about treating patients with HIV infections/AIDS: the student perspective. J Dent Educ 2003;67(6):630-40.

18. Seacat JD, Litt MD, Daniels AS. Dental students treating patients living with HIV/AIDS: the influence of attitudes and HIV knowledge. J Dent Educ 2009;73(4):437-44.

19. Rohn EJ, Sankar A, Hoelscher DC, et al. How do socialpsychological concerns impede the delivery of care to people with HIV? Issues for dental education. J Dent Educ 2006;70(10):1038-42.

20. Brondani MA, Paterson R. Teaching lesbian, gay, bisexual, and transgender issues in dental education: a multipurpose method. J Dent Educ 2011;75(10):1354-61.
21. Hamershock RA, Rajabiun S, Fox JE, et al. Dental students' HIV/AIDS-related knowledge, attitudes, and intentions: impact of the U.S. Health Resources and Services Administration's community-based dental partnership program. J Dent Educ 2014;78(8):1106-17.

22. Yengopal V, Naidoo S. Do oral lesions associated with HIV affect quality of life? Oral Surg Oral Med 2008;106:66-73.

23. Driscoll JM, Hoffman MA. Exploring attitudes of white dental students regarding willingness to treat people with HIV. J Dent Educ 1997;61(9):717-26.

24. Bennett ME, Weyant RJ, Simon M. Predictors of dental students' belief in the right to refuse treatment to HIVpositive patients. J Dent Educ 1993;57(9):673-9.

25. Anderson DG, Call RL, Vojir CP. Differences in HIV knowledge and attitudes between first- and fourth-year dental students. J Dent Educ 1994;58(8):668-72.

26. Borsum KM, Gjermo PE. Relationship between knowledge and attitudes regarding HIV/AIDS among dental school employees and students. Eur J Dent Educ 2004;8(3):105-10

27. Erasmus S, Luiters S, Brijlal P. Oral hygiene and dental students' knowledge, attitude, and behavior in managing HIV/AIDS patients. Int J Dent Hyg 2005;3:213-7.

28. Anderson JI, Patterson AN, Temple HJ, Inglehart MR. Lesbian, gay, bisexual, and transgender (LGBT) issues in dental school environments: dental student leaders' perceptions. J Dent Educ 2009;73(1):105-18.

29. Aguilar E, Fried J. Enhancing dental and dental hygiene student awareness of the lesbian, gay, bisexual, and transgender population. J Dent Hyg 2015;89(1):11-6.

30. Wanchek T, Cook BJ, Anderson EL, Valachovic RW. Annual ADEA survey of dental school seniors: 2014 graduating class. J Dent Educ 2015;79(9):1108-28.

31. Obedin-Maliver J, Goldsmith ES, Stewart L, et al. Lesbian, gay, bisexual, and transgender-related content in undergraduate medical education. JAMA 2011;306(9):971-7.

32. More FG, Whitehead AW, Gonthier M. Strategies for student services for lesbian, gay, bisexual, and transgender students in dental schools. J Dent Educ 2004;68(6): 623-32.

33. Behar-Horenstein LS, Morris DR. Dental school administrators' attitudes towards providing support services for LGBT-identified students. J Dent Educ 2015;79(8): 965-70.

34. Herek GM. Hate crimes and stigma-related experiences among sexual minority adults in the United States: prevalence estimates from a national probability sample. J Interpers Violence 2009;24(1):54-74.

35. Commission on Dental Accreditation. Accreditation standards for dental education programs. 2016. At: www.ada org/ /media/CODA/Files/predoc.ashx. Accessed 1 May 2016.

36. American Dental Hygienists Association. Code of ethics for dental hygienists. 2014. At: www.adha.org/resourcesdocs/7611_Bylaws and Code_of Ethics.pdf. Accessed 2 June 2016 .

37. Hardigan PC, Succar CT, Fleisher JM. An analysis of response rate and economic cost between mail- and webbased surveys among practicing dentists: a randomized trial. J Community Health 2012;37:383-94. 